\title{
Application of headspace solid-phase microextraction followed by gas chromatography-mass spectrometry to determine short-chain alkane monocarboxylic acids in aqueous samples
}

\author{
Anna Banel • Marta Wasielewska • Bogdan Zygmunt
}

Received: 7 September 2010 /Revised: 26 October 2010 / Accepted: 2 November 2010 /Published online: 25 November 2010

(C) The Author(s) 2010. This article is published with open access at Springerlink.com

\begin{abstract}
In this study, a procedure was developed to determine short-chain alkane monocarboxylic acids (SCMAs) in aqueous samples using headspace solid-phase microextraction (HS-SPME) followed by gas chromatography (GC) coupled with mass spectrometry (MS). A Stabilwax-DA capillary column $(30 \mathrm{~m} \times 0.32-\mathrm{mm}$ inner diameter, $0.50-\mu \mathrm{m}$ film thickness) was used for GC separation and a $60-\mu \mathrm{m}$ poly (ethylene glycol) fiber was used to isolate SCMAs from water and introduce them into the gas chromatograph. Parameters of HS-SPME, analyte desorption, and GC-MS analysis were selected and an analytical procedure was proposed. Limits of quantitation were on the order of about $0.2 \mathrm{mgL}^{-1}$. As an example of the application of the procedure, SCAMs were determined in municipal wastewater at different steps of treatment.
\end{abstract}

Keywords Short-chain alkane monocarboxylic acids .

Headspace $\cdot$ Solid-phase microextraction .

Gas chromatography-mass spectrometry - Wastewater

\section{Introduction}

Short-chain alkane monocarboxylic acids (SCMAs) containing two to seven carbon atoms in a molecule are analytes of interest in environmental chemistry, wastewater treatment, municipal

Published in the special issue Focus on Analytical Science in Poland (VIIIth Polish Conference on Analytical Chemistry) with Guest Editor Pawel Koscielniak.

A. Banel $\cdot$ M. Wasielewska $\cdot$ B. Zygmunt $(\square)$

Department of Analytical Chemistry, Chemical Faculty,

Gdańsk University of Technology (GUT),

11/12 G. Narutowicza Street,

80-233 Gdańsk, Poland

e-mail: banelka@wp.pl solid waste disposal, etc. [1]. SCMA total content has generally been determined by titration [2-4] or spectrophotometry $[5,6]$. Electrophoresis $[7,8]$, gas chromatography (GC) [9-11], and liquid chromatography [12], mainly ion chromatography [13], are applied to determine individual acids. GC is the method of choice to separate SCMAs in free form and as derivatives. Clean aqueous samples can be directly injected into a gas chromatograph to determine SCMAs, possibly after filtering off solid particles. Often GC determination of SCMAs in water must be preceded by matrix exchange and possibly an increase in analyte concentration. For this purpose, distillation, solvent extraction, solid-phase microextraction (SPME), and gas extraction (static headspace and purge and trap) have been used $[1,5,14,15]$.

A convenient isolation technique is SPME, which is quite inexpensive, time-efficient, and solvent-free and hence environmentally friendly [14]. In SPME, analytes are extracted into a thin fused-silica fiber coated with the extraction phase by immersing it in liquid and gas samples or in the headspace of solid and liquid samples (headspace SPME) [16]. The latter approach is very useful when the aqueous sample (e.g., raw wastewater) contains particulate matter and/or fiber-contaminating or fiber-damaging substances [17, 18]. Most of the commercially available fibers except for a poly(ethylene glycol) (PEG) fiber have been tested for extraction of SCMAs from aqueous samples.

Abalos et al. [11] used a 75- $\mu \mathrm{m}$ polydimethylsiloxane/ Carboxen (PDMS/CAR) fiber to extract SCMAs from the headspace of urban wastewater. Application of GC with flame ionization detection to determine the analytes gave limits of detection (LODs) on the order of $675 \mu \mathrm{gL}^{-1}$ for ethanoic acid and from 6 to $54 \mu \mathrm{gL}^{-1}$ for $\mathrm{C}_{3}-\mathrm{C}_{4}$ acids. $\mathrm{GC}-$ mass spectrometry (MS) with negative ion chemical ionization permitted lower LODs of $150 \mu \mathrm{gL}^{-1}$ for ethanoic acid and $2 \mu \mathrm{gL}^{-1}$ for higher acids $\left(\mathrm{C}_{3}-\mathrm{C}_{7}\right)$ to be obtained 
[10]. Yo [19] determined $C_{1}-C_{7}$ SCMAs in water, applying a $65-\mu \mathrm{m}$ Carbowax/divinylbenzene fiber for direct extraction and GC-MS with electron beam ionization for the analysis. The LODs ranged from 0.03 to $11.0 \mathrm{mM}$.

A polyacrylate fiber, which is very polar, efficiently extracted free $\mathrm{C}_{2}-\mathrm{C}_{5}$ acids from air (LOD 50-100 $\mathrm{ngL}^{-1}$ with $\mathrm{GC}$ with flame ionization detection). The LODs were much lower (below $1 \mathrm{ng} / \mathrm{L}$ with $\mathrm{GC}$ with electrochemical detection) when extraction was accompanied by in-fiber derivatization

The objective of this study was to develop and apply a procedure to determine SCMAs in aqueous samples using headspace SPME with a fiber for sampling and GC-MS for the analysis. Parameters of extraction (time, temperature, agitation rate, sample volume), and the time and temperature of desorption in the gas chromatograph injector were selected. The procedure was validated and applied to analyze municipal wastewater at different steps of treatment.

\section{Experimental}

Chemicals and solutions

Acid standards containing two to seven carbon atoms in a molecule of either $99.8 \%$ or $99.5 \%$ purity were purchased from Fluka (Switzerland). Methyl tert-butyl ether was from Merck (Germany). Stock standard solutions of each analyte were prepared by dissolving an acid standard in methyl tert-butyl ether. These solutions were mixed and diluted to the required concentration to give a standard solution. Standard aqueous samples were made by spiking purified water with the standard solution. A standard mixture of $\mathrm{C}_{1}-\mathrm{C}_{7}$ SCMAs $(10 \mathrm{mM})$ in water was obtained from Supelco (USA); it was diluted with water to produce organic-solvent-free standard aqueous samples.

Sodium chloride and 96\% sulfuric acid, both "pure for analysis" grade, were from Polskie Odczynniki Chemiczne (Poland).

\section{Real samples}

Municipal wastewater was sampled into 0.5-L HDPE bottles (Kautex) at the wastewater treatment plant at three sites: after leaving the grate, from the initial settling tank, and from the pipe discharging treated wastewater

Before use the bottles were carefully cleaned, rinsed with reverse osmosis purified water (Milli-Q A10 Gradient/Elix system, Millipore, Bedford, MA, USA), and rinsed twice with the sampled medium. They were filled to the brim with the wastewater to be analysed and transported to the laboratory in ice-cooled boxes (within $4 \mathrm{~h}$ ), then the samples were acidified and stored at $4{ }^{\circ} \mathrm{C}$.
Solid-phase microextraction

Aqueous samples (standard or real) were placed in $15-\mathrm{mL}$ glass vials with PTFE/silicone septa (Supelco, 27159). The $60-\mu \mathrm{m}$ PEG and $85-\mu \mathrm{m}$ PDMS/CAR fibers were from Supelco. They were conditioned in an injection port of the gas chromatograph before use at 240 and $300^{\circ} \mathrm{C}$, respectively. The fibers were exposed to the headspace of a sample kept at a selected temperature for a set time, retracted into a needle, and introduced into the gas chromatograph.

GC-MS instrumentation and analysis

A Thermo Finnigan Trace GC gas chromatograph equipped with a split/splitless injector coupled with a TRACE DSQ quadrupole mass spectrometer was used. SCMAs were desorbed from the fiber in a gas chromatograph splitless injection port with a $1 \mathrm{~mm}$ inner diameter liner. The injector temperature was 230 and $300{ }^{\circ} \mathrm{C}$ for PEG and PDMS/CAR fibers, respectively. A Restek Stabilwax-DA (cross-bond PEG treated with nitroterephthalic acid) open tubular capillary column $(30 \mathrm{~m} \times 0.32 \mathrm{~mm} \times 0.50 \mu \mathrm{m})$ was used for separation. The oven temperature program was as follows: $40{ }^{\circ} \mathrm{C}(3 \mathrm{~min}), 40{ }^{\circ} \mathrm{C} / \mathrm{min}$ to $180{ }^{\circ} \mathrm{C}(1 \mathrm{~min})$, $10{ }^{\circ} \mathrm{C} / \mathrm{min}$ to $230{ }^{\circ} \mathrm{C}(1 \mathrm{~min})$. The helium carrier gas flow rate was $1.5 \mathrm{mLmin}^{-1}$. The temperature of the transfer line and that of the electron impact ion source $(70 \mathrm{eV})$ were 230 and $240{ }^{\circ} \mathrm{C}$, respectively. MS was performed in full spectrum scanning mode $(\mathrm{m} / \mathrm{z} 40-400)$ and in selected ion monitoring (SIM) mode. The ions selected for the acids were as follows: ethanoic - 43, 45, 60; propanoic - 45, 57, 74; methylpropanoic-43, 73, 88; n-butanoic-60, 73; 3methylbutanoic - 41, 60, 87; $n$-pentanoic - $60,73,87 ; n$ hexanoic-60, 73, 87; $n$-heptanoic-41, 60, 73 .

\section{Results and discussion}

\section{GC separation}

SCMAs are very polar compounds and a polar StabilwaxDA column was selected for separation. The temperature program was given in the previous section. The selection of the initial column temperature and its run time was crucial for good peak shape and separation of the most volatile acids. The conditions tested were 35,40 , and $45^{\circ} \mathrm{C}$ kept for 3 and $5 \mathrm{~min}$; an initial temperature of $40^{\circ} \mathrm{C}$ maintained for 3 min was the best condition.

\section{Desorption}

The acids extracted into the PEG fiber from the headspace of an aqueous standard sample of $250 \mathrm{mgL}^{-1}$ concentration 
of each acid were desorbed for 3 and 5 min at injector temperatures ranging from 210 to $250{ }^{\circ} \mathrm{C}$ (change every $10{ }^{\circ} \mathrm{C}$ ) and the peak areas were measured; 3 min desorption at $230{ }^{\circ} \mathrm{C}$ was selected. Under these conditions the desorption from the fiber was performed twice for each extraction event. Standard samples of three different concentrations of each acid, i.e., 250,25 , and $1 \mathrm{mgL}^{-1}$, were analyzed. Peak areas of particular acids on the second desorption chromatograms were never larger than $0.5 \%$ of those obtained in the first desorption. This suggests that only trace, if any, amounts of extracted SCMAs remained on the fiber after the first desorption event and can be neglected as they are smaller than the experimental errors.

Desorption from the PDMS/CAR fiber was conducted at $300{ }^{\circ} \mathrm{C}$ as proposed by Abalos et al. [11].

\section{Headspace SPME}

\section{Fiber}

Free SCMAs are polar and, according to the "rule of thumb," a polar fiber coating should be the first choice. A $60-\mu \mathrm{m}$ PEG fiber (Supelco) was selected. It was shown to give results similar to those for the $85-\mu \mathrm{m}$ PDMS/CAR fiber, whose successful use for the most volatile SCMAs has already been reported.

\section{Extraction parameters}

The parameters taken into consideration were temperature, time, sample volume, and salt addition.

\section{Temperature}

The amounts of acids extracted (peak areas) at 25, 35, and $45{ }^{\circ} \mathrm{C}$ were compared. Higher temperatures were not used to avoid high water vapor content in the headspace, which can shorten the PEG fiber lifetime. In the tests, $8 \mathrm{~mL}$ sample in a $15-\mathrm{mL}$ vial and an extraction time of $40 \mathrm{~min}$ were applied. Two opposite effects determine the dependence of the extraction yield on temperature: raising the temperature increases the fraction of analyte transferred from a sample into its headspace but it decreases the fraction transferred from the headspace to the fiber. For $\mathrm{C}_{2}-$ $\mathrm{C}_{6}$ acids the highest yield was at $25^{\circ} \mathrm{C}$; only heptanoic acid extraction was the best at $45{ }^{\circ} \mathrm{C}$. A temperature of $25^{\circ} \mathrm{C}$ was chosen for extraction.

\section{Extraction profiles}

Extraction profiles in the range up to $50 \mathrm{~min}$ at a selected temperature of $25{ }^{\circ} \mathrm{C}$ and an assumed sample volume of $8 \mathrm{~mL}$ were determined. The sample was agitated with a magnetic stirrer at a rate of $1,200 \mathrm{rpm}$. As the results in Fig. 1 show, extension of the extraction time beyond $40 \mathrm{~min}$ does not give a noticeable increase in the peak areas; so $40 \mathrm{~min}$ was chosen as an analytical protocol parameter.

\section{Sample volume}

The amounts of acids extracted into the PEG fiber (peak areas) were measured for standard samples with volumes of 2,5 , and $8 \mathrm{~mL}$ in a $15-\mathrm{mL}$ vial; the concentration of each acid in the sample was $25 \mathrm{mgL}^{-1}$ and the extraction time was $40 \mathrm{~min}$. The largest peak areas were obtained for $2-\mathrm{mL}$ samples and this volume was selected as a procedure parameter.

\section{Salt addition}

From results of previous studies, addition of $0.75 \mathrm{~g} \mathrm{NaCl}$ to a 2-mL sample considerably decreases the solubility of
Fig. 1 Time profiles of extraction of short-chain alkane monocarboxylic acids into poly (ethylene glycol) fiber

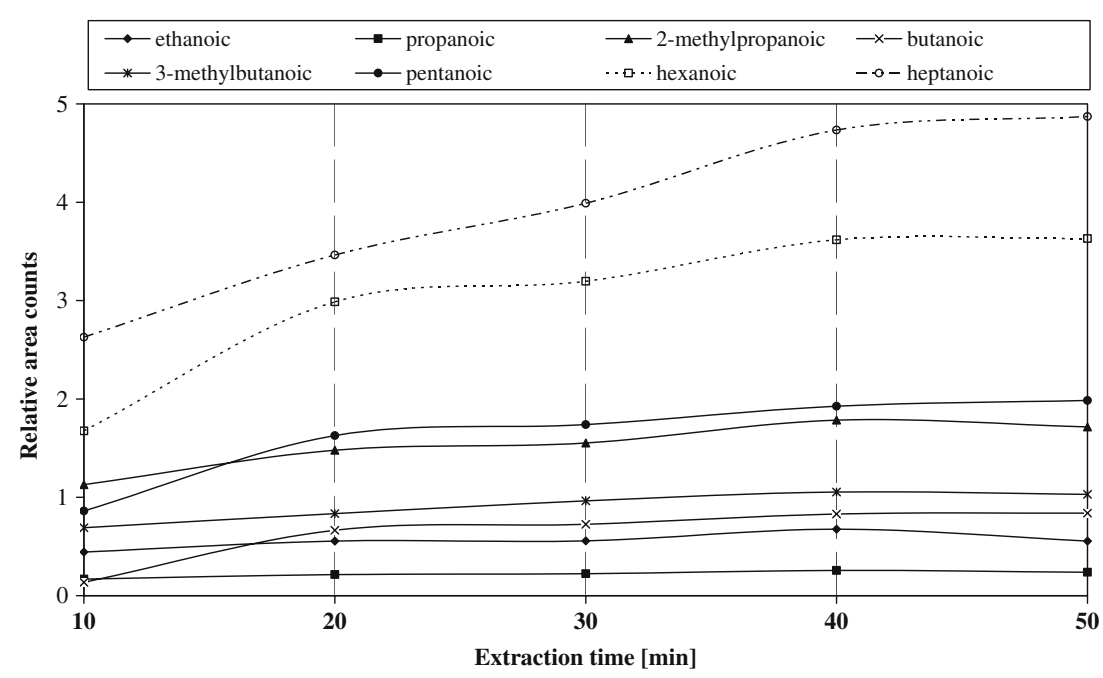


Table 1 Comparison of the limits of detection $(L O D)$ and limits of quantitation $(L O Q)$ of different acids for poly(ethylene glycol) (PEG)-coated fiber and polydimethylsiloxane/Carboxen $(P D M S / C A R)$-coated fiber

SCMAs short-chain alkane monocarboxylic acids,

\begin{tabular}{llllll}
\hline SCMAs & \multicolumn{2}{l}{ PEG } & & \multicolumn{2}{l}{ PDMS/CAR } \\
\cline { 2 - 3 } \cline { 5 - 6 } & LOD $\left(\mathrm{mgL}^{-1}\right)$ & LOQ $\left(\mathrm{mgL}^{-1}\right)$ & & LOD $\left(\mathrm{mgL}^{-1}\right)$ & LOQ $\left(\mathrm{mgL}^{-1}\right)$ \\
\hline Ethanoic & 0.051 & 0.15 & 0.20 & 0.60 \\
Propanoic & 0.040 & 0.12 & 0.03 & 0.090 \\
2-Methylpropanoic & 0.017 & 0.051 & 0.05 & 0.15 \\
$n$-Butanoic & 0.064 & 0.19 & 0.28 & 0.84 \\
3-Methylbutanoic & 0.047 & 0.14 & 0.04 & 0.12 \\
$n$-Pentanoic & 0.017 & 0.051 & 0.06 & 0.18 \\
$n$ n-Hexanoic & 0.026 & 0.078 & & 0.04 & 0.12 \\
$n$-Heptanoic & 0.035 & 0.10 & 0.08 & 0.24 \\
\hline
\end{tabular}

SCMAs [20]. The addition of the same amount was included in the protocol.

Detection, identification, and quantitation

In samples of high concentration, SCMAs were identified by comparing the retention times and the mass spectra of peaks with those of unknowns. In SIM mode, retention time identification was supported by the intensity ratio of two to three characteristic ions selected for monitoring. Quantitative analysis was based on SIM mode chromatograms, which were simpler owing to increased selectivity.

\section{Linearity and precision}

Working standard solutions of $\mathrm{C}_{1}-\mathrm{C}_{7}$ acids in water with concentration in the range from 0.10 to $300 \mathrm{mgL}^{-1}$ prepared from the commercial standard mixture were analyzed according to the complete protocol developed (see "Experimental"). Linear regression was used to describe the response-concentration dependence. The best fittings were observed when the concentration range was divided into two segments depending on the acid; the first for concentrations close to the LODs. The regression coefficients were never lower than 0.9917 and the coefficients of variation were not larger than $6 \%$.
LODs and limits of quantitation

LODs were calculated from calibration functions [21] using Eq. 1:

$\mathrm{LOD}=\frac{3.3 S}{b}$,

where $S$ is the residual standard deviation of the calibration function and $b$ is the slope of the first linear function.

The limits of quantitation (LOQs) defined as 3 times the LOD were acid-dependent; they were lower than $0.15 \mathrm{mgL}^{-1}$ for aqueous standard samples (Table 1). For comparison, LOQs for the same protocol are also given in Table 1.

\section{Real samples}

The procedure developed was applied to determine SCMAs in municipal wastewater sampled after leaving the grate, from the primary settling tank, and from a discharge pipe (treated wastewater).

The concentrations of individual acids were determined by the external standard method. To standard and real samples 2-ethylbutanoic acid $\left(25 \mathrm{mgL}^{-1}\right)$, not formed in nature, was added to exclude some biased results. In a few cases, the method of standard addition was applied to test if matrix components influenced the results to a noticeable
Table 2 Content of SCMAs in wastewater samples from different steps of treatment

\begin{tabular}{llll}
\hline SCMAs & \multicolumn{2}{l}{ Concentration $\left(\mathrm{mgL}^{-1}\right) \pm U($ average \pm extended uncertainty $)$} \\
\cline { 2 - 4 } & Treated water & Primary settling tank & Grate \\
\hline Ethanoic & $3.1 \pm 0.13$ & $102 \pm 1.9$ & $43 \pm 1.3$ \\
Propanoic & $0.36 \pm 0.088$ & $19.6 \pm 0.88$ & $3.20 \pm 0.041$ \\
2-Methylpropanoic & $0.065 \pm 0.0045$ & $0.56 \pm 0.026$ & $0.25 \pm 0.017$ \\
n-Butanoic & $0.56 \pm 0.014$ & $3.14 \pm 0.062$ & $2.96 \pm 0.062$ \\
3-Methylbutanoic & $0.8 \pm 0.10$ & $2.76 \pm 0.056$ & $0.48 \pm 0.011$ \\
$n$-Pentanoic & $<$ LOD & $<$ LOD & $<$ LOD \\
$n$-Hexanoic & $<$ LOD & $<$ LOD & $<$ LOD \\
$n$-Heptanoic & $<$ LOD & $<$ LOD & $<$ LOD \\
\hline
\end{tabular}


degree. In this case, SCMAs were added to real samples as a mixture of the aqueous standard solution. Since the differences were small as compared with errors of analysis, the data obtained (Table 2) were based on external standard calibration.

The results show that in all wastewaters, ethanoic acid was the most abundant. The second most abundant was propanoic acid. As can be expected, the concentration of acids was the lowest in treated wastewater and the highest in the primary settling tank.

\section{Conclusions}

A PEG-coated SPME fiber can be used to sample SCMAs containing two to seven carbon atoms in a molecule from the headspace of aqueous samples and to introduce the extracted analytes into a gas chromatograph. When GC-MS (SIM) is used for the analysis, SCMAs can be determined at a concentration above tenths of a milligram per liter. Repeatability expressed as the coefficient of variation was not larger than $6 \%$. The selectivity of the analytical procedure is sufficient to analyze samples of very complex matrices (e.g., wastewater). The example of the application was the determination of SCMAs in municipal wastewater at different steps of treatment. Some samples contained particular matter, high molecular weight organic substances and inorganics, and also interfering volatile organics. In all the samples, ethanoic, propanoic, 2-ethylpropanoic, $n$ butanoic, and 3-methylbutanoic acids were determined. In treated wastewater, the concentrations of the acids were more than an order of magnitude lower than in the samples collected at other sites. Ethanoic acid was always predominant. The concentrations of $n$-pentanoic, $n$-hexanoic, and $n$-heptanoic acids were below the LODs.

Acknowledgements This work was financially supported by the Polish Ministry of Science and Higher Education (grant NN523
230535). A.B. was partially funded by the Marshal Office of Pomorskie Voivodeship. The authors thank Sylwia Godlewska, Moosa Faniband, and Teeka Ram Pokhrel, a student preparing an M.Sc. thesis, for some help with the experimental work.

Open Access This article is distributed under the terms of the Creative Commons Attribution Noncommercial License which permits any noncommercial use, distribution, and reproduction in any medium, provided the original author(s) and source are credited.

\section{References}

1. Peldszus S (2006) In: Nollet LML (ed) Chromatographic analysis of the environment. CRC/Taylor \& Francis, Boca Raton, pp 453-511

2. Lahav O, Loewenthal RE (2000) Water SA 26:389-392

3. Bozkurt S, Moreno L, Neretnieks I (2000) Sci Total Environ 250:101-121

4. Sponza DT, Agdag ON (2004) Process Biochem 39:2157-2165

5. Siedlecka EM, Kumirska J, Ossowski T, Glamowski P, Gołębiowski M, Łajdus J, Kaczyński Z, Stepnowski P (2008) Pol J Environ Stud 17:351-356

6. Ozmihci S, Kargi F (2010) Int J Hydrogen Energy 35:6674-6 680

7. Chi FH, Lin PHP, Leu MH (2005) Chemosphere 60:1262-1269

8. Teng SX, Tong ZH, Li WW, Wang SG, Sheng GP, Shi XY, Liu XW, Yu HQ (2010) Appl Microbiol Biotechnol 87:2365-2372

9. Wang J, Long MC, Zhang ZJ, Chi LN, Qiao XL, Zhu HX, Zhang ZF (2008) Chemosphere 71:195-202

10. Abalos M, Bayona JM (2000) J Chromatogr A 891:287-294

11. Abalos M, Bayona JM, Pawliszyn J (2000) J Chromatogr A 873:107-115

12. Argun H, Fikret Kargi F (2010) Int J Hydrogen Energy 35:61706178

13. Merve Oguz TM, Robinson KG, Layton AC, Sayler GS (2006) Water Res 40:665-674

14. Giecewicz J, Zygmunt B (2003) Chem Inz Ekol 10:1125-1138

15. Banel A, Zygmunt B (2008) Chem Inz Ekol 15:7-28

16. Pan L, Pawliszyn J (1997) Anal Chem 69:196-205

17. Pan L, Chong JM, Pawliszyn J (1997) J Chromatogr A 773:249-260

18. Feng L, Huang Y, Wang H (2008) J Chromatogr Sci 46:577-584

19. Yo S-P (1999) Chemosphere 38:823-834

20. Zygmunt B, Banel A (2009) Chem Anal (Warsaw) 54:339-348

21. Konieczka P, Namieśnik J (2009) In: Lochmuller CH (ed) Quality assurance and quality control in the analytical chemical laboratory - a practical approach. CRC/Taylor \& Francis, Boca Raton, pp 131-216 